\title{
Cultura y comunicación
}

\section{Culture and communication}

\author{
Zoila Marlubeth Guzmán Hurtado* \\ Escuela Profesional de Ciencias de la Comunicación, \\ Universidad de San Martín de Porres, Perú
}

\section{Resumen}

Se abre el debate sobre el peligro de relativizar la palabra cultura. A pesar de la pluralidad de significados, es importante llegar a consensos con la finalidad de lograr que la humanidad evolucione y construya una sociedad más equitativa donde afloren los valores y la ética; llevados como estandarte para preservar la vida humana y el medioambiente. El interaccionismo simbólico demuestra que el ser humano continuamente genera procesos de significación. En este contexto, la ausencia o carencia de educación familiar, formación escolar y académica, genera que los seres procesen equivocadamente sus emociones llegando al individualismo más cruel.

El ser humano, preocupado por la evolución científica, olvida la evolución espiritual, esa que alimenta la cultura y preserva a la especie humana según los cánones de su esencia como persona. Es evidente la falta de empatía y el individualismo que se expresa en egoísmo y dificultad para mirar a otra persona como semejante. Por lo tanto, es necesario comprometerse con el rescate de la cultura humana

Palabras clave: comunicación, cultura, sociedad, lenguaje, interaccionismo simbólicos. 


\begin{abstract}
The present research discusses the danger of minimizing the word culture. Although it has many different meanings, it is important to reach a consensus to ensure that humanity continues its path towards evolution, thus building a more equitable society, where values and ethics emerge as a Gold Standard to preserve the environment. The symbolic interactionism shows that human beings continuously generate meaning-making processes. In this scenario, the absence or lack of family education, and school and academic training, causes human beings to process their emotions in a wrong way, going as far as the cruelest individualism.
\end{abstract}

Human beings, concerned about scientific evolution, forget about the spiritual evolution, which feeds culture according to the canons of their essence as people. It is evident the lack of empathy and the individualism that are revealed in the form of selfishness and difficulty to view others as equals. Therefore, we must commit ourselves to rescue human culture.

Keywords: communication, culture, society, language, symbolic interactionism.

\title{
Introducción
}

La cultura humana se ve opacada por las malas decisiones de los propios seres humanos. La soberbia no ha permitido, ni permite, ver los graves daños provocados al ecosistema y a la sociedad, como por ejemplo la contaminación ambiental. El caso de George Floyd, un afroestadounidense de 46 años que murió a consecuencia del violento arresto por parte de la policía en Minneapolis, Minnesota, grafica como los medios de comunicación ya no generan productos para la familia, ni mucho menos para los niños; lo mismo sucede por la corrupción en los poderes de los Estados y la lista es demasiado larga. En la actualidad, la pandemia ha develado mayores carencias y frustraciones. 
¿Qué está pasando con el ser humano? Se ha trastocado el significado que le atribuye a las cosas. Todos los días se conocen hechos de asesinatos, tráfico de drogas, violencia intrafamiliar, racismo, etc. Una realidad de la que no es ajena el Perú.

En el contexto peruano el flagelo que preocupa de sobremanera a los ciudadanos es la inseguridad. En el Informe técnico - Estadística de seguridad ciudadana, del Instituto Nacional de Estadística e Informática (INEI, s.f.), se señala que los delitos más comunes son el robo de dinero, cartera, celular, autos; estafa, amenaza e intimidación, maltrato y ofensa sexual; asaltos en los negocios, secuestro y extorsión. En suma una cultura que es destruida, en la que no se puede hablar de cultura de violencia (como algunos estudiosos del tema la llaman), porque la violencia no es parte de la cultura.

En esta investigación, se plantea recuperar el verdadero sentido de la cultura humana, explorando su significado, observando los hechos sociales e interpretándolos por medio del interaccionismo simbólico. El objetivo es establecer el relativismo simbólico de la palabra cultura como un valor ético para la democracia y como base de la comunicación social.

\section{Del formalismo: un intento por definir la palabra cultura}

La Real Academia Española, en la última edición de su diccionario (2014), define el término cultura como el conjunto de conocimientos científicos, industriales, manifestaciones artísticas, literarias, modos de vida y costumbres que se expresan en la vida de un pueblo.

Tylor (1976), homologa cultura con civilización y considera en su significado a toda manifestación adquirida por el hombre y la sociedad. Él acuña una de las definiciones clásicas de cultura y actualmente tiene el mismo sentido:

La cultura o civilización, en sentido etnográfico amplio, es ese todo complejo que incluye el conocimiento, las creencias, el arte, la moral, el derecho, las costumbres y cualesquiera otros hábitos 
y capacidades adquiridos por el hombre en cuanto miembro de una sociedad.

El creador de la llamada antropología estructural, Lévi-Strauss, según Bacco (s.f.), pondera el lenguaje, la mujer y los bienes materiales como lo más preciado que la humanidad ha generado; señala que el intercambio de estos valores define la cultura.

Para Simmel (como se citó en Levine, 1971), cultura se refiere al cultivo de los individuos, por medio de su agencia, de las formas externas que han sido objetivadas en el curso de la historia. En el ámbito de la filosofía y la sociología, se denomina agencia a la capacidad que posee un agente (una persona $u$ otra identidad) para actuar en un mundo.

Según Malinowski (1984), cultura es «el conjunto integral constituido por los utensilios y bienes de los consumidores, por el cuerpo de normas que rige los diversos grupos sociales, por las ideas y artesanías, creencias y costumbres» (p. 49). Integra en cultura a toda herramienta y bienes creados por el ser humano, así como el cuerpo jurídico que regenta a este como miembro de una sociedad y las ideas, creencias y costumbres que produce este grupo social.

Por otra parte, Williams (como se citó en Hall, 1994) identifica dos significados de cultura:

1. Es el conjunto de descripciones disponibles con que las sociedades dan sentido y reflexionan acerca de sus experiencias comunes; en este sentido, la cultura es ordinaria, común, ya no el dominio de unos cuantos. Esto significa que no hay forma de describir la realidad más que por medio de los vocabularios disponibles en un momento histórico; ni el arte escapa a esta determinación, puesto que forma parte de los procesos con los que una sociedad se reproduce a sí misma.

2. Se entiende a la cultura de forma más antropológica como práctica social, toda una forma de vida. Pero más que una simple descripción de las costumbres y hábitos de un grupo social, se trata de analizar cómo la cultura está imbricada en todas las prácticas sociales, porque es «la suma de sus interrelaciones» (Williams, como se citó en Hall, 1994). Esta forma 
de conceptualizar a la cultura es una toma de posición frente a las definiciones idealistas que la entienden simplemente como conjunto de ideas, y complica la metáfora base/superestructura del marxismo clásico al ubicar a la cultura en el centro de la reflexión como una praxis dinámica que se manifiesta de distinta manera en toda la actividad humana. Esta veta culturalista de los estudios culturales emplea el concepto de experiencia para referirse a las formas como son vividas las relaciones y conflictos sociales, «dónde y cómo la gente experimenta sus condiciones de vida, las define y responde a ellas» (Hall, 1994). Es decir, la cultura como el conjunto de experiencias comunes derivadas de la práctica social de los individuos de una comunidad que no se limita a la enumeración de sus hábitos y costumbres, sino que se esfuerza en comprender la interrelación de aquellas prácticas sociales.

El concepto de cultura se opone al de la naturaleza, y es la relación del hombre lo que las hace diferenciables, si bien se oponen estos conceptos son inseparables; en tanto la cultura resulta ser el conjunto de soluciones que el hombre ha encontrado en su enfrentamiento con la naturaleza y dominación progresiva sobre ella (Golte, 2001, p. 15).

Entonces, la subjetividad debe ser entendida como el espacio donde se articulan lo biológico-pulsional y lo simbólico, en el lugar en el que se entreteje lo social y lo personal, donde se define la individualidad. En efecto la subjetividad es organizada por la cultura en la medida en que las significaciones sociales, permiten una regulación viable de la impulsividad. Es decir, la cultura encuentra restricciones en lo real de lo afectivo. No se trata, entonces, de un sistema simbólico omnipotente y de una interioridad maleable. Tanto la cultura como la subjetividad deben ser concebidas como realidades complejas y heterogéneas cuya dinámica está atravesada por la acomodación, la tensión y el conflicto (Portocarrero y Komadina, 2001, p. 15).

\section{Entropía social y cultural}

Durante los siglos que tiene el ser humano sobre el planeta tierra siempre trató de perpetuar sus mensajes mediante la comunicación, un legado viviente que acompañaba su evolución. Al principio, el hombre utilizó su cuerpo como la principal herramienta, como un lienzo, hasta que el cerebro y la mente le 
permitieron crear el lenguaje y posteriormente la escritura, con estos dos primeros instrumentos el ser humano se abrió paso al mundo formal o mundo de las ideas; por tanto, pudo transformar el mundo físico y adaptarlo a sus necesidades. Mientras más numerosos eran los miembros de las ciudades, los seres humanos veían sus sentidos limitados. Para solucionar el inconveniente emprenden una larga carrera de dependencia de la evolución tecnológica para todos los procesos de intercambio de información, olvidándose que ellos mismos son la esencia de la comunicación y, por ende, la fuente de donde emana la cultura humana.

Por consiguiente, la cultura necesita de las interdependencias entre los individuos que conforman los distintos grupos, tribus, aldeas, ciudades, naciones y países, para que pueda construir la red que cohesiona a la sociedad. Al respecto, Berlo (2000) afirma que la interdependencia es un proceso complejo, es una relación de dependencia recíproca o mutua entre dos individuos, donde primero debe existir la interdependencia para que se produzca la comunicación.

Se deduce que la comunicación sin ruido permite la manifestación de la cultura, lo contrario sucede durante la presencia de ruido; entendiendo ruido como toda manifestación que irrumpe los procesos comunicativos en distintas formas y niveles, desnaturalizando la construcción de la cultura; es necesario entonces que los seres humanos convivan armoniosamente para satisfacer sus necesidades. Primero, se gestionan las metas individuales, que no deben alejarse de las metas colectivas para producir una sana convivencia. Pero la historia del ser humano está marcada por una serie de conflictos, que han generado atraso en su ciclo evolutivo, entrando a una entropía informativa, que tiene como consecuencia una entropía social y por lo tanto cultural.

Por ejemplo, en 1969 como humanidad se empezó la carrera espacial. En las proyecciones para los años 80, la humanidad sería una civilización con viajes interplanetarios e interespaciales. Entonces, ¿qué se proyectaba para los dos primeros decenios del siglo XXI? El ser humano hasta el día de hoy no puede solucionar las imperfecciones que avergüenza su progreso en sectores vitales, vemos que hay gente muriendo de hambre, niños víctimas de todo tipo de violencia, naciones en conflicto, hermanos matándose en una guerra que no es de ellos, calentamiento global, individualismo, etc., que acaban con 
todo aquello que humanizó y enalteció a los humanos como seres superiores del planeta tierra. Aquello que se construyó en nombre de la cultura.

A propósito de lo señalado, Leuridan (2019) describe magistralmente como el individualismo y la vulgaridad van mermando los valores y la ética, para concretar la malignización de lo bueno. Desde el punto de vista filosófico brinda un panorama contundente y real de lo que atraviesa la humanidad al desprenderse de los valores y la ética, con funestas consecuencias en la cultura. Afirma: «cuando se respetan las normas morales sigue existiendo la conciencia de la injusticia. Perdiéndose esta última se pierde la cultura» (p. 33).

La injusticia en sus distintas formas destruye la cultura, porque va acompañada de corrupción, marginación, hambre, amoralidad, inmoralidad, falta de empatía, asesinato, aborto, genocidio y tantos otros. El caos y la anarquía estallan a cada momento y se apoderan de aquellos individuos que le pierden el sentido a todo lo que les rodea. A nivel mundial, se vive en incertidumbre desde antes de la pandemia, la autoridad ha perdido su valor y, por lo tanto, todo sentido. Demasiadas familias no están dotando a la sociedad de individuos que puedan socializar armoniosamente.

\section{La teoría de la pérdida del sentido}

Tomando en principio a la familia, es increíble que ahora se recomiende, bajo el estandarte de la tolerancia, que los padres negocien con los hijos, iqué significado tiene la palabra negociar?, ¿los roles, deberes y obligaciones no tienen razón de ser en la estructura de la familia?, ¿cómo negociar con un niño que no sabe alimentarse, ni autorregularse?, ¿quién le da la pauta para que distinga entre lo bueno y lo malo?

De ese modo se empieza a fracturar el sentido y el valor de la palabra autoridad. Pero, son muchos elementos sociales inmersos en esta pérdida del sentido; por ejemplo, ¿cuál es el sentido de la palabra político?, su verdadero significado se ha perdido y no solamente en el Perú; ¿cuál es el sentido que otorgan los peruanos a la palabra justicia? La palabra cultura pierde sentido. 
$\mathrm{Al}$ respecto Habermas (2001):

Y lo mismo que Weber, Horkheimer ve el resultado de este desarrollo de las imágenes del mundo en la formación de esferas culturales de valor que obedece cada una su propia legalidad específica: «Esta división de esferas culturales se debe a que la verdad objetiva universal es sustituida por una razón formalizada, relativista en lo más hondo». A la subjetivización de la razón responde la irracionalización de la moral y del arte. (p. 441)

En la presente investigación, la palabra cultura tiene grandes derroteros para definirla en la filosofía relativista, utilitarista y pragmática; así como, las subordinadas a estas que aglutinan manifestaciones como la falta de educación en el hogar como la cuna de valores - formación ética y la falta de formación académica.

La vulgaridad ha generado un viraje lingüístico, que lleva al sinsentido total, se ha relativizado los significados de muchas palabras que constituyen los pilares de la cultura como familia, matrimonio, arte, música, estética, educación, bien, mal, etc.

\section{¿Y qué dice la semiótica?}

Para Eco (2000) la cultura tiene dos formas más extremas: «La Cultura es sólo comunicación» y la «cultura no es otra cosa que sistema de significaciones estructuradas» (p. 44).

Por lo tanto, la cultura es un producto de la comunicación, del intercambio de un conjunto de significaciones, es así que cobra importancia el valor o sentido otorgado a esas significaciones estructuradas, cabe decir que si las palabras no son utilizadas en sus verdaderas acepciones o definiciones, se cae en un relativismo y hasta en el caos. El individualismo es enemigo de la cultura -como se estableció anteriormente-, por eso, es importante el respeto por el derecho a la educación establecido en la Declaración de los Derechos del Hombre y del Ciudadano (1789), para que cada persona pueda intervenir en su propia gobernanza y estar consciente de su destino. 
Desde que existe sociedad, todas las funciones se transforman automáticamente en signos de esa función. Cabe resaltar que el signo es una representación mental de algún objeto (Barthes, como se citó en Eco, 2000, p. 47).

La utilidad del signo está en aquel significado concreto imbricado en la ocurrencia ocasional en las que el signo está efectivamente realizado. Según Wittgenstein el significado es lo que importa del signo (como se citó en Quezada, 1996, p. 153).

Surge la pregunta ¿dónde y cómo se aprenden esos signos?, tomando en consideración que los antiguos tenían la convicción de que la educación y la cultura no constituían un arte formal o una teoría abstracta, distintos de la estructura histórica de la vida de una nación. En esta reflexión se destacan los problemas éticos de comunicación en la construcción social de la paz. La pluricultural y la multiglosia son motivo de aislamiento y desequilibrio, en lugar de ser elementos contundentes de riqueza y diversificación creadora. La incomunicación trajo consigo los males que se ven hasta el día de hoy, de desconocimiento mutuo, desintegración, discriminación y explotación. Es necesario investigar, trabajar y contribuir en la enseñanza de la comunicación social y así enfrentar los álgidos problemas por los que atraviesa la sociedad (Quezada, 1996, pp. 153, 201, 202).

\section{¿En qué repara la comunicación?}

Mattelart y Neveu (2004) recogen del inventor de la filosofía de la educación Matthew Arnold (1822-1888) el pensamiento voluntarista de la salvación mediante la cultura:

Por los valores culturales y las normas estéticas e intelectuales de los que son portadoras, las grandes obras artísticas y literarias son «hijas de la luz». «Los hombres de cultura son los verdaderos apóstoles de la igualdad. Los grandes hombres de cultura son los que se apasionan por la difusión para que prevalezcan, para que, de un extremo a otro de la sociedad, se propaguen el mejor conocimiento, las mejores ideas de nuestro tiempo; los que han trabajado para despojar a ese saber de todo lo que era áspero, 
zafio, difícil, abstracto, profesional, excesivo; para humanizarlo, para que resulte eficaz más allá de la camarilla de gente culta y erudita, sin que por ello deje de ser el mejor conocimiento y el mejor pensamiento de la época, $y$, desde entonces, una verdadera fuente de templanza y de luz». (p. 25)

En esta arqueología de la palabra cultura se rescata un significado vital para la evolución y desarrollo humano y la peregrinación de la especie humana en el tercer planeta, es importante que se tenga en cuenta, al definir la palabra cultura, a toda característica que nos eleva tanto, en lo social como en lo espiritual. Ningún rasgo de la cultura debe llevar al desorden y al caos, por ello, las sociedades mediante la norma y la ley castigan todo acto que vaya contra el bienestar común. Pero la ley tiene un carácter coercitivo, más que de rehabilitación para la participación armoniosa de aquel que irrumpió en la sana convivencia (Mattelart y Neveu, 2004).

Para fomentar la verdadera articulación de la cultura en cada miembro del grupo social se debe formar su conciencia, educando al individuo como un ser psico-social-espiritual:

Stuart Mill entre otros, anteponen el riesgo del dominio del Leviatán estatal a la formación de las conciencias, sostiene que las escuelas públicas son las únicas que pueden dar la «mejor cultura de la nación», la que enseña la nobleza de los sentimientos y del espíritu. (Mattelar y Neveu, 2004, p. 26)

No se puede relativizar las definiciones del concepto cultura, ni relacionar significados que esgriman contenidos destructivos, caóticos o contra la supervivencia de la especie humana. Dejaría de ser cultura. La civilización humana, poco a poco va perdiendo su valía como animales superiores en este planeta (Mattelar y Neveu, 2004).

Así como no se puede relativizar el arte, no se debe relativizar la palabra cultura, para la subsistencia debe refrescarse la definición de la palabra cultura y redireccionar el camino a la evolución, la implementación será dura y de largo aliento. Arnold, trazó este camino desde el siglo XIX: 
La cultura, que es el estudio de la perfección, nos lleva a concebir la verdadera perfección humana como una perfección armoniosa, que desarrolla todos los aspectos de nuestra humanidad; y como una perfección general, que desarrolla todas las partes de la sociedad. (como se citó en Mattelar y Neveu, 2004, p. 27)

\section{El interaccionismo simbólico del término cultura}

George Herbert Mead elabora la teoría del interaccionismo simbólico que fue publicada en 1934 en el libro Mente, Self y la Sociedad, difundido por uno de sus alumnos. En esta obra se destaca el acto social como unidad principal de análisis. El significado se logra de la relación triádica que se desprende de los siguientes elementos: «un gesto inicial por parte del individuo, la respuesta a este gesto por otra persona y el resultado». Posteriormente, Blumer continúa el estudio de su maestro Mead y desarrolla los tres principios del interaccionismo simbólico: el significado, el lenguaje y el pensamiento (como se citó en Fernández y Galguera, 2009, p. 20).

Tanto Griffin (2009) como Littelejohn y Foss (2008) señalan que «la realidad social después de todo no es más que el acuerdo colectivo de un conjunto de significados» (como se citó en Fernández y Galguera, 2009, p. 20); resaltando que los interaccionistas simbólicos no niegan la existencia de objetos en el mundo real.

Por lo expuesto, es necesario entender cómo se tergiversa el significado de la palabra, o lo más grave, como un significado ausente construye un argumento que va contra la cultura. Por ejemplo, matar es un delito, el primer derecho que tiene todo ser humano es la vida, sin embargo, un grupo de mujeres exigen como derecho matar a su propio hijo. No se discute si hay acuerdo o desacuerdo con este grupo de mujeres que desean legalizar el aborto, violando todo tipo de derecho contra el concebido, el inocente de toda esta tragedia, el que no tiene voz, ni voto. Lo que se señala es que el conjunto de significados sobre derecho, aborto, asesinato, madre, etc. termina siendo un acuerdo cerrado para un sector de la población; la incoherencia salta a la vista porque en su doble discurso proclaman el lema ni una menos y isi el bebé que llevan en su vientre es una niña? 


\section{Figura 1}

Colectivos que protestan en contra del feminicidio $y$, sin embargo, sus pañuelos verdes reclaman el derecho para asesinar al más indefenso del planeta, un niño o una niña por nacer.

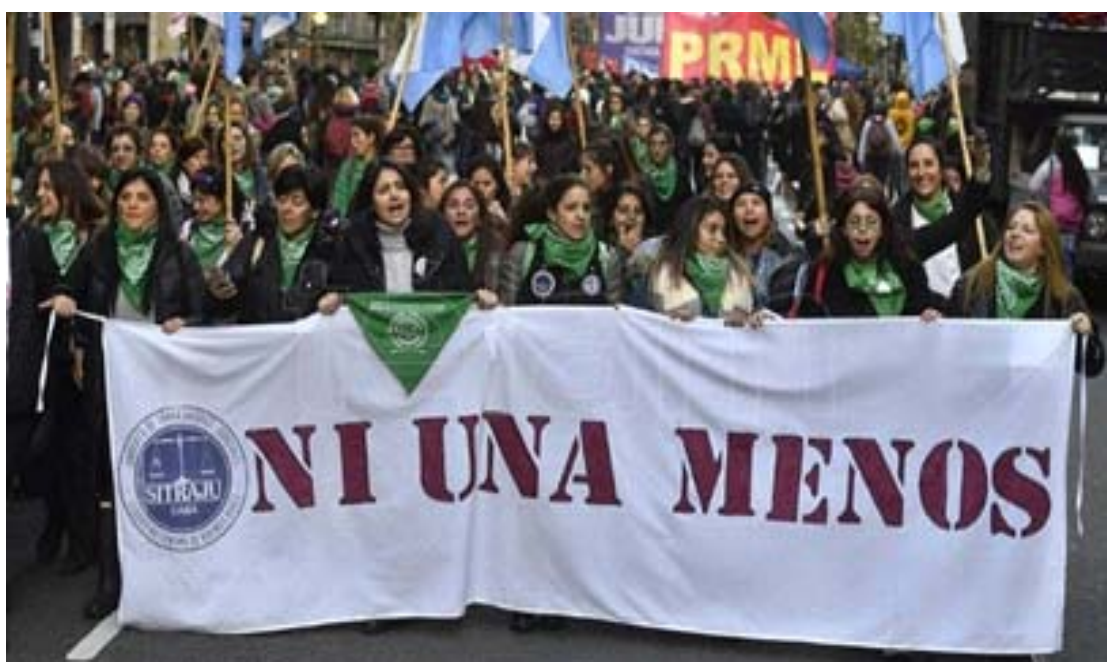

Nota. Telam. Agencia de noticias: https:/www.telam.com.ar/notas/201806/287190-masivamarcha-de-ni-una-menos-que-suma-el-reclamo-por-el-aborto-legal.html

El lenguaje, constituido por el vocabulario contiene definiciones, y en el proceso de comunicación se dan los significados. Med (como se citó en Fernández y Galguera, 2009) establece lo siguiente:

La asignación de un significado es la base de la sociedad humana. Los interaccionistas afirman que la extensión del conocimiento depende de la amplitud del vocabulario: entre más palabras más conocimiento. Sin embargo, la interacción simbólica no es sólo un medio para la expresión de la inteligencia, sino también es la forma o manera como interpretamos al mundo ... a medida que vamos interactuando simbólicamente con los demás, vamos significando el mundo y desarrollando un universo de discurso. (p. 21)

¿Cómo interpretan el mundo estás personas? La muerte es el fin de la vida, por ello causa dolor en los deudos y exige de todos los que van a presentar condolencias el máximo respeto. Definitivamente, la interpretación simbólica 
que hacen estas personas sobre la muerte de una amiga, tiene mucho que ver con la construcción de su lenguaje sobre la base de un vocabulario, que de acuerdo a las imágenes es totalmente contradictorio a los hechos. La cultura nos da esos espacios pertinentes para que puedan fluir nuestras emociones y sentimientos, es natural que la vida no se pueda convertir en una fiesta interminable, sea cual sea el momento que les toque vivir.

El pensamiento como proceso cognitivo modifica la interpretación simbólica del entorno, de nuestras creencias y de todo aquello que procesamos para entender nuestro mundo. El minding permite al individuo entrar en un diálogo consigo mismo (Mead, como se citó en Fernández y Galguera, 2009).

El tercer concepto de Blumer es el pensamiento. Es a través de los procesos del pensamiento que modificamos la interpretación simbólica. Los interaccionistas simbólicos describen el pensamiento como una conversación interior del individuo consigo mismo por medio de los gestos significantes ... Mead llamó a este diálogo interno minding. (Fernández y Galguera, 2009)

\section{Figura 2}

El sinsentido total hasta en el primer valor humano, la vida y su antagonismo la muerte.
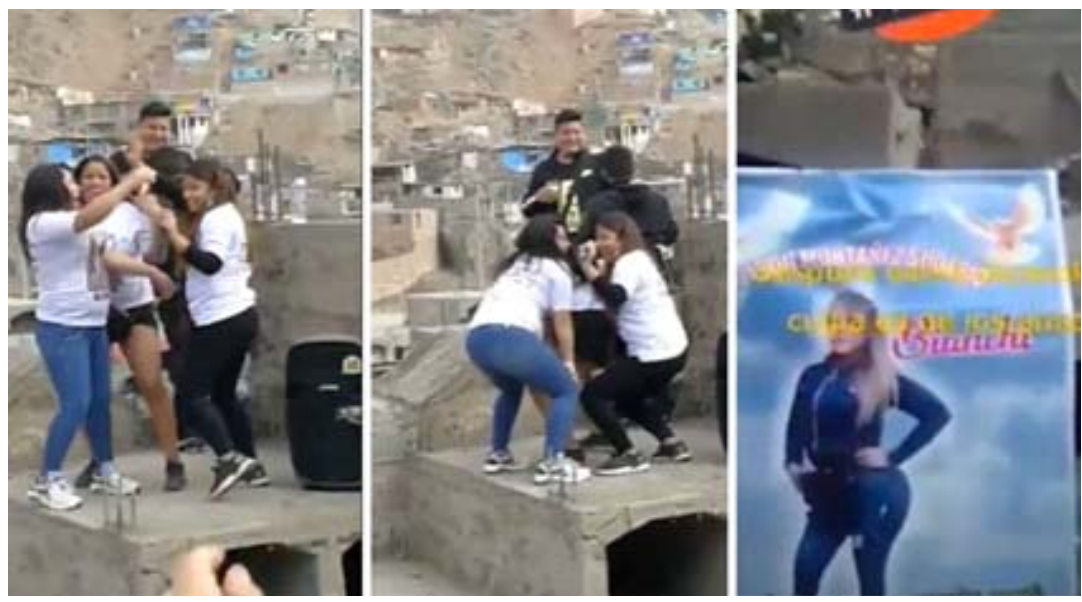

Nota. Diario el Trome. https://trome.pe/actualidad/los-olivos-asistentes-cementerio-cervezabailan-nicho-noticia/ 
Pero, ¿cuál es el significado de la palabra cultura? La respuesta es relativa, hay varias acepciones, no existe un consenso. En el Perú, el índice de lectura es mínimo, por lo tanto, el vocabulario es escaso. Definitivamente la única manera de aprender el lenguaje es de forma oral, como consecuencia, hay una pobreza de definiciones académicas o como mínimo formales. Mediante el pensamiento se elabora una interpretación simbólica, por lo que la interacción simbólica de la mayoría de los individuos está basada en situaciones emotivas, individualistas y a partir de sus necesidades, sin mediar por nadie más que por ellos mismos.

\section{La teoría de la acción comunicativa}

Un claro panorama sobre la construcción lingüística, rescatando la necesidad de instaurar una pragmática formal donde las palabras no tengan una descripción en el diccionario y otra significación en el imaginario colectivo es el que presenta Habermas (2001):

El deslinde lingüístico entre los planos de realidad que representan el «juego» y el «ir en serio», la construcción lingüística de una realidad ficticia, el chiste y la ironía, el uso traslaticio y paradójico del lenguaje, las alusiones, las revocaciones contradictorias de pretensiones de validez en el plano metalingüístico -todo ello se basa en una confusión intencionada de modalidades del ser-. La pragmática formal puede aportar a la aclaración de los mecanismos que el hablante necesita para dominar todo ello, mucho más que lo que puede aportar una simple descripción empírica, por exacta que sea, de los fenómenos a explicar. (p. 424)

Pero, no es solamente la palabra cultura la que sufre este ataque frontal, también lo sufre la palabra comunicación.

Otro tanto acaece con los fenómenos de distorsión sistemática de la comunicación. También aquí la pragmática formal puede contribuir a la clarificación de fenómenos que, de entrada, sólo pueden identificarse merced a una comprensión intuitiva, madurada por la experiencia clínica. Tales patologías de la 
comunicación pueden entenderse, en efecto, como resultado de una confusión entre acciones orientadas al éxito y acciones orientadas al entendimiento. (Habermas, 2001, p. 425)

La comunicación es sustancial para la evolución de la cultura, estos dos conceptos deben atenderse en sus verdaderas y auténticas acepciones, proteger nuestra humanidad es proteger nuestro lenguaje, nuestros significados y pensamientos, los seres humanos necesitamos de los otros para subsistir. La tarea es aprender a convivir con el otro de forma armoniosa, sin falsedad, sin engaños, pero todavía cuesta vivir en la verdad, es parte de la evolución. Si bien es cierto que no somos seres perfectos, somos perfectibles, es imperioso que entendamos la necesidad de vivir en la sociedad como comunidad para eliminar y evitar conflictos, y sobre todo, para que el egoísmo e individualismo no maltrate, ni deshumanice a la persona o ciudadano.

En situaciones de acción estratégica solapada, al menos uno de los participantes se conduce orientándose hacia el logro de sus particulares propósitos, pero hace creer a los demás que todos cumplen los supuestos de la acción comunicativa. Se trata del caso de manipulación a que nos hemos referido al hablar de los actos perlocucionarios. Por el contrario, el tipo de solución inconsciente de conflictos, que el psicoanálisis explica por medio de estrategias de defensa, acaba produciendo perturbaciones de la comunicación, simultáneamente en el plano intrapsíquico y en el plano interpersonal. En tales casos, al menos uno de los participantes se engaña a sí mismo al no darse cuenta de que está actuando en actitud orientada al éxito y manteniendo sólo una apariencia de acción comunicativa. El Tugar que en el marco de una teoría de la acción comunicativa corresponde a esta comunicación sistemáticamente distorsionada se desprende del esquema siguiente. (Habermas, 2001, p. 426) 
Figura 3

Habermas y la fórmula del engaño

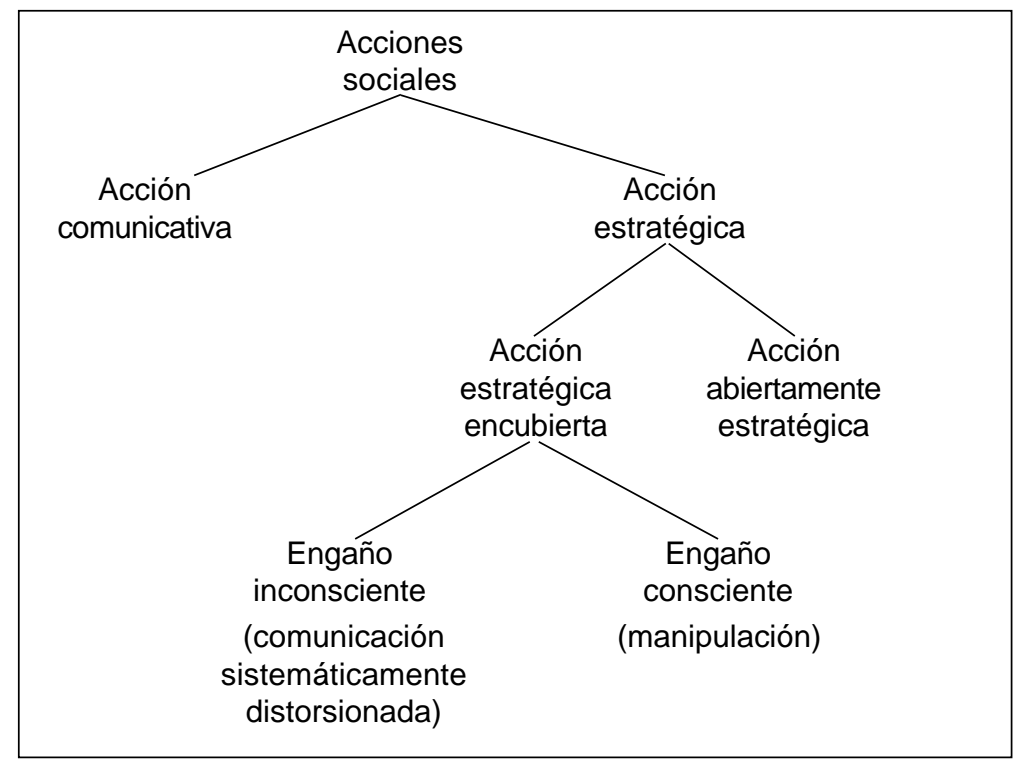

Nota. Habermas, 2001, p. 426.

Muchos políticos, y personas en general, están convencidos que el camino al éxito conlleva destruir a la competencia. Creer eso es mezquino ya que el éxito implica sacrificio, eficiencia, formación, capacitación, responsabilidad y otros atributos que demandan mucho trabajo, por eso se opta por el engaño (ver Figura 3).

\section{Salvando la comunicación salvamos la cultura humana}

Wolton (2006), en referencia a la comunicación, considera la necesidad de reconocer como enemigos a enfrentar (si realmente se desea auxiliarla), variables como la sociedad del espectáculo, las élites y la universidad, los conceptos blandos, la disputa entre antiguos y modernos, la ideología técnica, las cinco contradicciones de la comunicación, entre otras que la mantienen secuestrada. Por lo tanto, para derrotar al enemigo hay que conocerlo. 
Los enemigos de la cultura son:

a. El individualismo, deformación del espíritu colaborativo y solidario del ser humano, es la base de la destrucción de la cultura. Se camufla y se esconde en la demanda del llamado derecho de la mujer para abortar, que es el asesinato del inocente por nacer. Muchas madres reclaman el derecho de asesinar a su hijo concebido.

b. La falta de ética de las personas, de las empresas e instituciones públicas y privadas deforman la cultura; esto acarrea un costo económico por delitos de corrupción, pero también un costo moral para el país y los ciudadanos que observan y conviven con la falta de honestidad e integridad. ¿Qué legado se le deja a las nuevas generaciones. Niños, jóvenes y toda la población presencian la impunidad con la que se manejan los temas judiciales; casos de personas procesadas e incluso sentenciadas que dan discursos o son entrevistados como expertos en alguna materia.

c. Medios de comunicación, que en lugar de fomentar la cultura y moral de la nación, lanzan producciones mediocres y con faltas a la ética y a la Ley N. ${ }^{\circ} 28278$.

d. Familias que han descuidado su rol de dotar a la sociedad de personas sanas, capaces de convivir en forma armoniosa.

e. Jóvenes y adultos que le han dado la espalda a su condición como ciudadanos, con el viejo adagio no soy político, evitan asumir compromisos y responsabilidades.

Es de vital importancia darle un sentido consensuado y real a la palabra cultura, defenderla de toda ambigüedad polisémica. Aquí el Estado juega un rol importante en la formación de los ciudadanos, por lo que es necesario generar políticas de protección para la familia; y que esta se restablezca como la cuna de los valores, donde se forme a los seres humanos para crear una sociedad más justa, que defienda los valores democráticos. Asimismo, los medios de comunicación deben manejarse con ética y dentro de lo establecido por las leyes. 


\section{Conclusiones}

El concepto de cultura debe ser tomado a partir de su origen: cultivo, que se refiere a los rasgos que caracterizan a un determinado grupo humano para satisfacer sus necesidades, generando el bienestar común y del medioambiente.

Es preciso, defender la cultura humana conceptual, semántica y teóricamente, no relativizar el término, ni aceptar conceptos ambiguos que se conviertan en motivo de la destrucción del espíritu humano. La cultura es el mejor termómetro para medir el progreso y la evolución de la humanidad. La familia requiere ser protegida por una legislación que promueva la sana convivencia y continuar con la tarea en los colegios. 


\section{Referencias}

Bacco, B. (s.f.). Claude Lévi-Strauss. Comunidad Virtual Russell. http://www.comunidadrussell.com/ default.asp?contenidos/textos/levi-strauss.html

Berlo, D. (2000). El proceso de la comunicación: Introducción a la teoría y la práctica (2. ${ }^{a}$ ed.). El Ateneo.

Eco, U. (2000). Tratado de semiótica general (5. ${ }^{a}$ ed.). Lumen.

Fernández, C. y Galguera, L. (2009). Teorías de la comunicación. Mc Graw Hill.

Golte, J. (2001). Cultura, racionalidad y migración andina. Instituto de Estudios Peruanos.

Habermas, J. (2001). Teoría de la acción comunicativa, I. Racionalidad de la acción y racionalización social (3. ${ }^{2}$ ed.). Taurus.

Hall, S. (1994). Estudios Culturales: dos paradigmas. Causas y azares, 1, 1-18. https://estudioscultura.wordpress. com/category/teoricos/stuart-hall/\#: : :text=Hall\%20identifica\%20dos\%20significados\%20del,el\%20dominio \%20de\%20unos\%20cuantos.

Instituto Nacional de Estadística e Informática (INEI). (s.f.). Estadística de Seguridad Ciudadana (Informe Técnico). https://www.inei.gob.pe/biblioteca-virtual/boletines/estadisticas-de-seguridad-ciudadana/1/

Leuridan, J. (2019). El sentido de las dimensiones éticas de la vida. Fondo Editorial, Universidad de San Martín de Porres.

Levine, D. (Ed.). (1971). Simmel: On individuality and social forms. University Press.

Malinowski, B. (1984). Una teoría científica de la cultura. Sarpe.

Mattelart, A. y Neveu, E. (2004). Introducción a los estudios culturales. Paidós.

Portocarrero, G. y Komadina, J. (2001). Modelos de Identidad y sentidos de pertenencia en el Perú y Bolivia. Instituto de Estudios Peruanos.

Quezada, O. (1996). Semiosis, conocimiento y comunicación. Universidad de Lima, Fondo de Desarrollo Editorial. Tylor, E. B. (1976). Cultura Primitiva. Ayuso.

Wolton, D. (2006). Salvemos la comunicación. Gedisa. 